Eko Wahyu Budiman, Rahmad Pulung Sudibyo, Istis Baroh. 2016. Analisis Kelayakan

Usaha Budidaya Apel (Studi Kasus Di Desa Bumi Aji Kecamatan Bumi Aji Kota Batu )

Journal Viabel Pertanian. (2018), 12(1) 1-8

\title{
ANALISIS KELAYAKAN USAHA BUDIDAYA APEL (STUDI KASUS DI DESA BUMI AJI KECAMATAN BUMI AJI KOTA BATU
}

\author{
Eko Wahyu Budiman'), Rahmad Pulung Sudibyo ${ }^{2)}$, Istis Baroh ${ }^{2)}$ \\ ${ }^{1)}$ Dosen Program Studi Agribisnis Universitas Islam Balitar Blitar \\ ${ }^{2)}$ Dosen Fakultas Pertanian Universitas Muhammadiyah Malang
}

\begin{abstract}
ABSTRAK
Technological developments have brought apple commodities into business commodities that can improve the well-being of the actors involved, as well as highly selective apple plants, can only grow well and well in certain areas of East Java, such as Batu and Nongkojajar. Data analysis method using Quantitative Descriptive analysis to know the level of financial feasibility of business, calculated by analysis of Acceptance and Cost (B / C ratio), Internal Rate of Return (IRR), Net Present Value (NPV), and Payback Period (PP). As for the marketing aspect using qualitative descriptive analysis. Based on research conducted in Bumiaji Village, Bumiaji Subdistrict of Malang City, that cultivation of apple is feasible to be cultivated with NPV of Rp. 471,825,898, using the current bank interest of $12 \%$, and also for Gross $B$ / C ratio of 2.4633, Net $B$ / C ratio of 4.6088, while IRR of 34.43\%. As for the refund cost incurred taken from the amount of Net Benefit in the 4th year until the 13th year that is $R p .1 .129 .796 .500$. so that in the 14th to the 26th year there is a net profit of a total of Rp 1,270,351,050, -.
\end{abstract}

Keyword : IRR, NPV, PP

\section{PENDAHULUAN}

Meskipun bukan asli tanaman dari Indonesia, apel termasuk salah satu jenis buah yang populer disamping jeruk dan mangga. Selain dikonsumsi dalam bentuk buah segar yang sangat bermanfaat untuk kesehatan, kelezatan apel juga bisa dinikmati dalam bentuk aneka olahan seperti sari buah, cider (fermentasi sari apel), dodol, keripik, dan lain-lain yang banyak dijajakan di Kota Wisata Batu. Serat apel juga mencegah penyakit jantung serta mengontrol berat badan dan kadar kolesterol.

Apel yang dibiakkan secara invitro mengandung senyawa fenol yang dapat mencegah kanker dan menunjukkan aktivitas antioksidan. Buah apel merupakan salah satu jenis buah yang disukai oleh banyak orang. 
Eko Wahyu Budiman, Rahmad Pulung Sudibyo, Istis Baroh. 2016. Analisis Kelayakan Usaha Budidaya Apel (Studi Kasus Di Desa Bumi Aji Kecamatan Bumi Aji Kota Batu )

Journal Viabel Pertanian. (2018), 12(1) 1-8

Rasa manis dan segar dari buah apel membuat banyak orang menyukainya walaupun mungkin tanpa menyadari khasiat buah apel itu sendiri. Dan mungkin, ini juga yang membuat harga buah apel dipasaran lebih mahal dibanding dengan buah lainnya. Harga apel lokal seperti apel malang lebih mahal dari pada apel impor umumnya. Menurut data Biro Pusat Stastitik di tahun 2011, jumlah konsumsi dalam negeri sebesar 391685 ton, dari 57,9 \% buah lokal dan 42,1\% buah impor.

\section{METODE PENELITIAN}

Penelitian ini dilakukan di desa Bumiaji Kecamatan Bumiaji Kota Batu pemilihan lokasi ini dilakukan secara sengaja dengan alasan lokasi tersebut adalah salah satu tempat budidaya apel/sentra apel, serta dekat dengan wisata petik buah apel yang ada di Kota Batu, mayoritas masyarakat disitu adalah petani apel, maka mempermudah peneliti dalam pengambilan data dilapang.

Data penelitian ini diambil secara lansung pada responden, petani atau sekelompok petani apel. Teknik pengambilan sampel dilakukan dengan metode purposive sampling, yaitu cara pengambilan sampel secara sengaja. Jenis data yang digunakan dalam penelitian ini adalah:

- Data Primer

- Wawancara

- Observasi

- Data Sekunder

- Instansi - instansi terkait, misalnya kantor desa setempat.

- Pustaka - pustaka

- Internet

Metode Analisis Data

Analisis finansial adalah analisis kelayakan yang melihat dari sudut pandang petani sebagai pemilik. Analisis finansial diperhatikan didalamnya adalah dari segi cash-flow yaitu perbandingan antara hasil penerimaan atau penjualan kotor (gross-sales) dengan jumlah biaya-biaya atau (total cost) yang dinyatakan dalam nilai sekarang untuk mengetahui kriteria kelayakan atau keuntungan suatu proyek. Hasil finansial sering juga disebut "private returns". Kriteriakriteria yang biasa digunakan untuk mengetahui kelayakan suatu proyek diantaranya adalah : Net Present Value (NPV), Internal Rate of Return (IRR), Net Benefit-Cost Ratio (Net B/C Ratio), dan Payback Period (Soetriono,2006).

Analisis Sensitivitas

Bertujuan untuk melihat apa yang akan terjadi dengan hasil analisa proyek jika ada sesuatu kesalahan atau perubahan dalam perhitungan biaya atau Benefit. 
Eko Wahyu Budiman, Rahmad Pulung Sudibyo, Istis Baroh. 2016. Analisis Kelayakan

Usaha Budidaya Apel (Studi Kasus Di Desa Bumi Aji Kecamatan Bumi Aji Kota Batu )

Journal Viabel Pertanian. (2018), 12(1) 1-8

\section{PEMBAHASAN}

Tingkat umur petani merupakan faktor yang sangat mempengaruhi kemampuan fisik petani dalam mengolah usaha taninya atau aktivitas yang lainnya. Biasanya semakin tua umur seseorang maka semakin banyak pengalamannya tetapi semakin menurun pula produktifitasnya, dan cenderung lebih sulit menerima teknologi dan inovasi baru dan sebaliknya dengan usia muda mudah untuk menerima hal - hal yang baru.

Semakin besar tanggungan keluarga maka semakin besar pula biaya yang akan dikeluarkan oleh petani sehingga petani dituntut untuk bekerja lebih keras untuk memenuhi kebutuhannya.

Tabel 5.1 Distribusi Responden Berdasarkan Umur

\begin{tabular}{|c|c|c|c|}
\hline No & Umur & $\begin{array}{c}\text { Jumlah } \\
\text { Petani }\end{array}$ & $\begin{array}{c}\text { Prosentase } \\
(\%)\end{array}$ \\
\hline 1 & $30-40$ th & 2 & $8 \%$ \\
\hline 2 & $40-50$ th & 5 & $19 \%$ \\
\hline 3 & $>50$ th & 19 & $73 \%$ \\
\hline Total & & 26 & $100 \%$ \\
\hline
\end{tabular}

Sumber: Data diolah Primer, 2013

Tabel 5.3 Jumlah tanggungan keluarga koresponden

\begin{tabular}{|c|c|c|c|}
\hline No & $\Sigma$ Keluarga & $\Sigma$ Petani & Prosentase \\
\hline 1 & $2-3$ & 9 & $34,6 \%$ \\
\hline 2 & $4-6$ & 17 & $65,4 \%$ \\
\hline \multicolumn{2}{|c|}{ Total } & 26 & $100 \%$ \\
\hline
\end{tabular}

Sumber: Data diolah Primer, 2013

Dalam menjalankan sebuah aktifitasnya, petani akan mengeluarkan berbagai jenis biaya diantaranya adalah biaya bahan, upah langsung dimana kedua biaya ini disebut biaya operasional maintenance. Biaya bahan dan upah langsung ini meliputi pupuk organik, pupuk kimia (ZA, NPK, UREA, TSP, Mutiara, Ponska), obat-obatan pestisida dan tenaga kerja. 
Eko Wahyu Budiman, Rahmad Pulung Sudibyo, Istis Baroh. 2016. Analisis Kelayakan

Usaha Budidaya Apel (Studi Kasus Di Desa Bumi Aji Kecamatan Bumi Aji Kota Batu )

Journal Viabel Pertanian. (2018), 12(1) 1-8

Investasi merupakan biaya yang dikeluarkan untuk proses produksi yang dimana tidak habis dalam satu kali proses produksi meliputi pembelian alat seperti sabet, cangkul, gunting, sprayer, selang dan benih, tetapi dalam penggunaan alat tersebut ada nilai penyusutan yang dimana rata - rata nilai penyusutannya 5 tahun atau penurunan nilai pada suatu alat setiap tahunnya, selama 5 tahun.

NPV merupakan selisih antara nilai sekarang (present value) dari manfaat (benefit) dari biaya (cost) pada tingkat suku bunga tertentu. Usaha dikatakan layak apabila $N P V>0$ berarti usaha layak untuk dijalankan. Secara sistematis, 
p-ISSN: 1978-5259 e-ISSN: 2527-3345

Copyright@UNISBA Blitar, http://viabel.unisbablitar.ejournal.web.id

Eko Wahyu Budiman, Rahmad Pulung Sudibyo, Istis Baroh. 2016. Analisis Kelayakan Usaha Budidaya Apel (Studi Kasus Di Desa Bumi Aji Kecamatan Bumi Aji Kota Batu )

Journal Viabel Pertanian. (2018), 12(1) 1-8

\begin{tabular}{|c|c|c|c|c|c|c|c|c|}
\hline \multirow[b]{2}{*}{ Benefit } & \multirow[b]{2}{*}{ Investasi } & \multirow[b]{2}{*}{$\mathrm{OM}$} & \multirow[b]{2}{*}{ Net Benefit } & \multirow{2}{*}{$\begin{array}{c}\text { DF } \\
12 \\
\%\end{array}$} & \multicolumn{4}{|c|}{ Discounted } \\
\hline & & & & & PV I & PV OM & PV B & PV NB \\
\hline & $21,450,000$ & $33,362,500$ & $-54,812,500$ & 1 & $21,450,000$ & $33,362,500$ & & $-54,812,500$ \\
\hline & $10,600,000$ & $36,750,000$ & $-47,350,000$ & 0.8828 & $9,357,680$ & $32,442,900$ & & $-41,800,580$ \\
\hline & $3,060,000$ & $5,310,000$ & $-8,370,000$ & 0.7971 & $2,439,126$ & $4,232,601$ & & $-6,671,727$ \\
\hline & $5,130,000$ & $18,465,000$ & $-23,595,000$ & 0.7117 & $3,651,021$ & $13,141,541$ & & $-16,792,562$ \\
\hline $2,800,000$ & $3,980,000$ & $15,600,000$ & $-16,780,000$ & 0.6355 & $2,529,290$ & $9,913,800$ & $1,779,400$ & $-10,663,690$ \\
\hline $200,000,000$ & $4,150,000$ & $35,432,500$ & $160,417,500$ & 0.5674 & $2,354,710$ & $20,104,401$ & $113,480,000$ & $91,020,890$ \\
\hline $120,000,000$ & $4,800,000$ & $18,039,000$ & $97,161,000$ & 0.5066 & $2,431,680$ & $9,138,557$ & $60,792,000$ & $49,221,763$ \\
\hline $131,250,000$ & $5,595,000$ & $34,873,000$ & $90,782,000$ & 0.5423 & $3,034,169$ & $18,911,628$ & $71,176,875$ & $49,231,079$ \\
\hline $184,800,000$ & $6,160,000$ & $41,608,000$ & $137,032,000$ & 0.4038 & $2,487,408$ & $16,801,310$ & $74,622,240$ & $55,333,522$ \\
\hline $116,662,000$ & $7,050,000$ & $45,484,000$ & $64,128,000$ & 0.3606 & $2,542,230$ & $16,401,530$ & $42,068,317$ & $23,124,557$ \\
\hline $190,680,000$ & $7,000,000$ & $43,785,000$ & $139,895,000$ & 0.3219 & $2,253,300$ & $14,094,392$ & $61,379,892$ & $45,032,201$ \\
\hline $140,000,000$ & $6,800,000$ & $34,214,000$ & $98,986,000$ & 0.2874 & $1,954,320$ & $9,833,104$ & $40,236,000$ & $28,448,576$ \\
\hline $200,000,000$ & $3,410,000$ & $9,537,000$ & $187,053,000$ & 0.2566 & 875,006 & $2,447,194$ & $51,320,000$ & $47,997,800$ \\
\hline $192,000,000$ & $4,490,000$ & $33,168,000$ & $154,342,000$ & 0.2291 & $1,028,659$ & $7,598,789$ & $43,987,200$ & $35,359,752$ \\
\hline $192,000,000$ & $5,500,000$ & $33,165,750$ & $153,334,250$ & 0.2046 & $1,125,300$ & $6,785,712$ & $39,283,200$ & $31,372,188$ \\
\hline $192,000,000$ & $6,280,000$ & $41,789,200$ & $143,930,800$ & 0.1826 & $1,146,728$ & $7,630,708$ & $35,059,200$ & $26,281,764$ \\
\hline $184,000,000$ & $5,625,000$ & $12,868,000$ & $165,507,000$ & 0.1631 & 917,438 & $2,098,771$ & $30,010,400$ & $26,994,192$ \\
\hline $160,000,000$ & $5,410,000$ & $34,965,000$ & $119,625,000$ & 0.1456 & 787,696 & $5,090,904$ & $23,296,000$ & $17,417,400$ \\
\hline $160,000,000$ & $5,700,000$ & $44,996,200$ & $109,303,800$ & 0.1301 & 741,000 & $5,849,506$ & $20,800,000$ & $14,209,494$ \\
\hline
\end{tabular}


Jurnal Viabel Pertanian Vol. 12 No.1 Mei 2018

p-ISSN: 1978-5259 e-ISSN: 2527-3345

Copyright@UNISBA Blitar, http://viabel.unisbablitar.ejournal.web.id

Eko Wahyu Budiman, Rahmad Pulung Sudibyo, Istis Baroh. 2016. Analisis Kelayakan Usaha Budidaya Apel (Studi Kasus Di Desa Bumi Aji

Kecamatan Bumi Aji Kota Batu )

Journal Viabel Pertanian. (2018), 12(1) 1-8

\begin{tabular}{|r|r|r|r|r|r|r|r|r|}
\hline $160,000,000$ & $7,850,000$ & $55,800,000$ & $96,350,000$ & 0.1161 & 911,385 & $6,478,380$ & $18,576,000$ & $11,186,235$ \\
\hline $128,000,000$ & $4,520,000$ & $24,369,000$ & $99,111,000$ & 0.1036 & 468,272 & $2,524,628$ & $13,260,800$ & $10,267,900$ \\
\hline $126,400,000$ & $4,236,000$ & $18,946,200$ & $103,217,800$ & 0.0925 & 391,830 & $1,752,524$ & $11,692,000$ & $9,547,647$ \\
\hline $160,000,000$ & $4,200,000$ & $20,509,300$ & $135,290,700$ & 0.0826 & 346,920 & $1,694,068$ & $13,216,000$ & $11,175,012$ \\
\hline $144,000,000$ & $8,700,000$ & $55,625,000$ & $79,675,000$ & 0.0736 & 640,320 & $4,094,000$ & $10,598,400$ & $5,864,080$ \\
\hline $152,000,000$ & $5,860,000$ & $33,966,800$ & $112,173,200$ & 0.0658 & 385,588 & $2,235,015$ & $10,001,600$ & $7,380,997$ \\
\hline $129,600,000$ & $4,260,000$ & $21,600,000$ & $103,740,000$ & 0.0588 & 250,488 & $1,270,080$ & $7,620,480$ & $6,099,912$ \\
\hline $3,366,192,000$ & $161,816,000$ & $816,228,450$ & $2,388,147,550$ & 7.9217 & $66,501,563$ & $255,928,543$ & $794,256,004$ & $471,825,898$ \\
\hline
\end{tabular}


Eko Wahyu Budiman, Rahmad Pulung Sudibyo, Istis Baroh. 2016. Analisis Kelayakan Usaha Budidaya Apel (Studi Kasus Di Desa Bumi Aji Kecamatan Bumi Aji Kota Batu )

Journal Viabel Pertanian. (2018), 12(1) 1-8

Bahwa keuntungan yang diperoleh dari DF 12\% sebesar Rp. 471.825.898, mengapa menggunakan DF $12 \%$ karena menyesuaikan dengan suku bunga bank yang berlaku, bila dilihat dari tabel di atas bahwa NPV yang di peroleh lebih besar dari pada 0 (NPV > 0) maka usaha budidaya apel di Desa Bumiaji Kecamatan Bumiaji Kota Batu layak untuk dijalankan.

Dalam perhitungan Net B/C Ratio diatas bahwa nilai Net B positif berbanding dengan nilai yang negative dengan Df $12 \%$ menghasilkan nilai sebesar 4,6088. Nilai Net B/C Ratio > 1 maka usaha budidaya apel di Desa Bumiaji Kecamatan Bumiaji Kota Batu layak untuk dijalankan. Artinya setiap Rp.10.000.000 modal yang ditanamkan oleh petani akan mendapatkan benefit sebesar Rp 46.088.000, artinya.

Gross Benefit/Cost Ratio (Gross B/C Ratio) dari perhitungan diatas bahwa nilai dari DF $12 \%$ adalah sebesar 2,4633 dari nilai benefit kotor dibagi dengan biaya yang telah dikeluarkan, atau $\mathrm{B} / \mathrm{C}$ ratio $>1$ maka usaha budidaya apel di Desa Bumiaji Kecamatan Bumiaji Kota batu layak untuk dijalankan.

Internal Rate of Return (IRR) menunjukan bahwa nilai NPV1 diperoleh dari NB dikalikan dengan Df $34 \%$ yang menghasilkan nilai positif mendekati 0 sebesar 2.526.055,54 dan DF 35\% yang menghasilkan nilai negatif mendekati 0 sebesar - 8.305.310,65 dan kemudian dimasukkan kedalam rumus mendapatkan hasil IRR sebesar 34,43\% yaitu bahwa pengembalian biaya usaha budidaya apel di Desa Bumiaji selama setahun sebesar 34,34\%. Sesuai dengan kriteria IRR maka usaha budidaya apel di Desa Bumiaji layak untuk dijalankan.

Payback Period $(P P)$ merupakan jangka waktu periode yang diperlukan untuk membayar kembali (mengembalikan) semua biaya-biaya yang telah dikeluarkan di dalam investasi suatu proyek. Dari perhitungan data primer biaya investasi sebesar Rp. 161.816.000 dan biaya operasional maintenance sebesar Rp. 816.228.450 dengan jumlah biaya total sebesar Rp. 978.044.450 dan Net Benefit yang dipeoleh sebesar Rp. 2.388.147.550 dari umur ekonomis tanaman 25 tahun. Untuk mengembalikan biaya-biaya yang telah dikeluarkan oleh petani apel, maka pengembalian diambil dari jumlah Net Benefit pada tahun ke 4 sampai tahun ke 13 yaitu sebesar Rp. 1.129.796.500. sehingga pada tahun ke 14 sampai tahun ke 26 diperoleh keuntungan bersih dengan

total sebersar Rp. 1.270.351.050,--

Analisis sensitivitas terhadap Net benefit setiap kenaikan harga produk sebesar $15 \%$, maka akan menaikkan NPV sebesar 8,77 \% . Dengan kata lain, bahwa penurunan harga produk apel sebesar 13,155\% akan menyebabkan NPV menjadi 0 .

Sensitifitas terhadap Operasional Maintenance (OM) Berdasarkan perhitungan diatas bahwa setiap kenaikan harga pupuk sebesar $151 \%$ menyebabkan NPV menjadi 0. Analisis sensitivitas variabel pupuk sebesar 30\% tidak terlalu sensitiv terhadap perubahan biaya produksi. 
Eko Wahyu Budiman, Rahmad Pulung Sudibyo, Istis Baroh. 2016. Analisis Kelayakan

Usaha Budidaya Apel (Studi Kasus Di Desa Bumi Aji Kecamatan Bumi Aji Kota Batu )

Journal Viabel Pertanian. (2018), 12(1) 1-8

\section{DAFTAR PUSTAKA}

AAK, 2001. Petunjuk Praktis Bertanam Buah-Buahan. Kanisius. Yogyakarta.

Abdul Halim, 2005. Analisis Investasi. Salemba Empat. Jakarta.

Kadariah, Karlina L, Gray C. 1999. Pengantar Evaluasi Proyek. Fakultas Ekonomi Universitas Indonesia. Jakarta.

Mulyadi,2002. Akutansi Manajemen. Salemba Empat. Jakarta.

Mulyadi P, Evaluasi Proyek. Liberty. Yogyakarta.

Soekartawi, 1987. Dasar-Dasar Evaluasi Proyek dan Petunjuk Praktis Dalam Membuat Evaluasi. PT Bina Ilmu. Surabaya.

Soekartawi, 1989. Prinsip dasar manajemen pemasaran hasil pertanian: teori dan aplikasinya. Rajawali. Jakarta

Soekartawi. 1993. Agribisnis: Teori dan Aplikasinya. Penerbit PT Raja Grafindo Persada. Jakarta.

Sudjarwanto, T. 1993. Penanganan Pasca Panen Buah-Buahan. Kumpulan

Kliping Panen dan Peluang Bisnis Buah. Pusat Informasi

Pertanian Trubus.Jakarta.

Sunarjono, Hendro.1986. Ilmu Produksi Tanaman Buah-buahan. Sinar Baru. Bandung.

Soetriono, 2006. Daya Saing Dalam Tinjauan Analisis. Bayu Media. Malang. 